\title{
Design Considerations of Resonant Network and Transformer Magnetics for High Frequency LLC Resonant Converter
}

\author{
Hwa-Pyeong Park*, Younggon Ryu*, Ki Jin Han* and Jee-Hoon Jung ${ }^{\dagger}$
}

\begin{abstract}
This paper proposes the design considerations of resonant network and transformer magnetics for $500 \mathrm{kHz}$ high switching frequency LLC resonant converter. The high power density can be effectively achieved by adopting high switching frequency which allows small size passive components in the converter. The design methodology of magnetizing inductance is derived for zero voltage switching (ZVS) condition, and the design methodology of the transformer and output capacitance is derived to achieve high power density at high operating frequency. Moreover, the structure of transformer is analyzed to obtain the proper inductance value for high switching operation. To verify the proposed design methodology, simulation and experimental results will be presented including temperature of passive and active components, and power conversion efficiency to evaluate dominant power loss. In addition, the validity of magnetics design will be evaluated with operating waveforms of the prototype converter.
\end{abstract}

Keywords: High switching frequency, LLC resonant converter, Transformer design, Power density

\section{Introduction}

These days, a LLC resonant converter is one of the most attractive topologies in the industrial fields such as LED, $\mathrm{TV}$, computer, and other home appliances. It has many advantages of fewer components than other topologies, small circulating current, and low switching losses using soft switching methods such as zero current switching (ZCS) for the secondary side diode, and zero voltage switching (ZVS) for a MOSFET as a main switch over entire load condition [1-10]. Moreover, the LLC converter is good for high frequency switching operation which is one of the latest trends of the switch mode power supply (SMPS). The high frequency switching operation makes the size of passive components small, which increases the power density of the converter. In addition, comparing with conventional hard-switching converters and asymmetrical half-bridge converter, the LLC resonant converter has small switching and conduction losses by the soft switching and the symmetric operation [11-15].

To operate the converter with optimal design in aspect of power density, the design considerations for high switching frequency should be derived. When the switching frequency increases, the size of passive components is proportionally decreasing [16-20]. The relationship between the crosssectional area of the transformer's core and the switching frequency should be investigated to design small-sized transformer properly under high frequency operation.

$\dagger$ Corresponding Author: School of Electrical and Computer Engineering, Ulsan National Institute of Science and Technology (UNIST), Korea. (jhjung@unist.ac.kr)

* School of Electrical and Computer Engineering, Ulsan National Institute of Science and Technology (UNIST), Korea.

Received: May 13, 2015; Accepted: October 26, 2015
Furthermore, the size of output capacitor can be decreased using the relationship among the effective series resistance (ESR), capacitance, and the switching frequency. They can be mathematically induced and be verified with simulation and experimental results.

Meanwhile, the magnetizing inductance should be designed adequately to obtain the ZVS condition, but conventional magnetizing inductance design method has higher error at high frequency operation. Therefore, high frequency magnetics should be considered in the design of the magnetizing inductance at the high switching frequency.

To design the transformer for high frequency switching, several design parameters should be considered. First, a proper size of the magnetic core has to be chosen with considering the saturation limit of the specific flux density. By adjusting the number of turns of the primary winding and the cross-sectional area of the core, proper magnetic core which can avoid the saturation at the switching frequency is selected. Second, the transformer should satisfy required values of the magnetizing inductance and the leakage inductance since the LLC resonant converter uses the inductances as the components of its resonant network. At high switching frequency, the required values of the inductances become smaller. To satisfy the small value of the magnetizing inductance, the structure of the magnetic core should have an air gap. In addition, the winding method should be changed to obtain the small value of the leakage inductance. With respect to all of those parameters, a suitable transformer should be designed to be applied to the LLC resonant converter properly for its high frequency operation.

In this paper, a prototype LLC resonant converter operating at $100 \mathrm{kHz}$ and $500 \mathrm{kHz}$ switching frequency is 
implemented to experimentally verify the validity of the proposed design methodology. To obtain optimal operating points at $100 \mathrm{kHz}$ and $500 \mathrm{kHz}$ switching frequency, the magnetizing inductance is separately designed. The temperature of passive and active components is measured to find out dominant power losses at high frequency operation. In addition, the validity of high-frequency magnetics design is evaluated with mathematical analysis. All the design considerations are verified by proper simulation and experimental results with a $300 \mathrm{~W}$ prototype LLC resonant converter operating at $100 \mathrm{kHz}$ and $500 \mathrm{kHz}$ switching frequencies.

\section{Design Considerations for Power Stage}

The conventional medium switching frequency LLC resonant converter has been designed with the relationship among Q-factor (Quality factor), voltage gain, and $\lambda$ which is defined as $L_{r} / L_{m}$, where $L_{r}$ is the leakage inductance and $L_{m}$ is the magnetizing inductance. The converter which has high $\lambda$ needs small frequency modulation to control the output voltage since the higher gain variation is introduced by the higher $\lambda$. High $\lambda$ has small conduction losses with small circulating currents, however it has a demerit under over-load condition because of non-monotonic gain curves.

Small $\lambda$ is convenient to control the output voltage under over-load condition, however, it requires high frequency modulation to obtain enough voltage gain. Moreover, small $\lambda$ has high conduction loss which comes from high circulating current. The Q-factor changed by load condition shows the sharpness of the voltage gain near the resonant frequency. Fig. 1 shows the scheme of the LLC resonant converter and Fig. 2 shows the voltage gain curve according

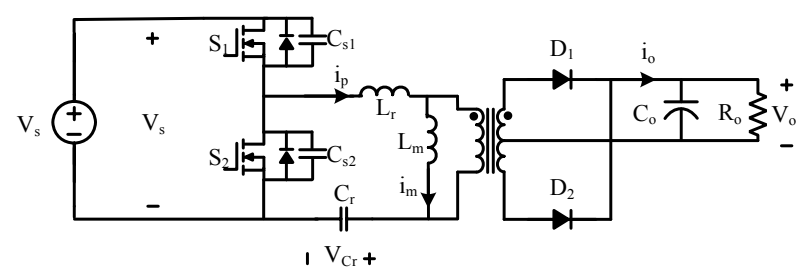

Fig. 1. Circuit diagram of the LLC resonant converter

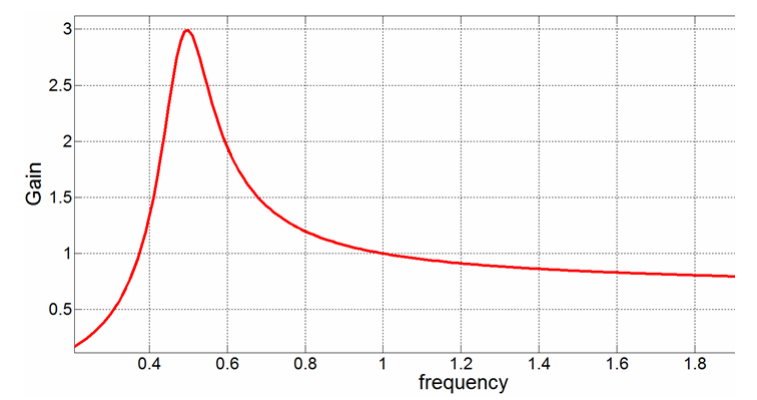

Fig. 2. DC gain characteristics of the LLC resonant converter to the switching frequency. In this section, design considerations of the resonant network and output capacitance of the LLC resonant converter for high frequency operation will be discussed.

\subsection{Design for soft switching condition}

To verify the validity of the proposed design methodology, a prototype converter is implemented with an analog controller (ST L6599) which has a fixed dead time (0.2-0.4 $\mu \mathrm{s})$. Comparing with the switching frequency of $500 \mathrm{kHz}$ $(2 \mu \mathrm{s})$ in the prototype converter, the dead time is longer than $10 \%$ of the switching frequency. Fig. 3 shows theoretical waveforms whose dead time from $t_{c}$ to $t_{e}$ is large enough to influence the shape of the primary current. The primary current cannot follow the magnetizing current during the dead time, and it is collapsed by the secondary parasitic capacitance before the end of the dead time.

From the above reasons, the conventional design method of the magnetizing inductance is not a proper to obtain the ZVS operation in the high switching frequency operation. Since the conventional design method is derived using the approximation of constant primary current during the dead time, it introduces considerable errors for the ZVS condition. From the conventional design method, the primary current can be expressed as follows:

$$
i_{p}\left(t_{c}\right)=\frac{n\left(V_{o}+V_{D f}\right) T_{s}}{4 L_{m}}
$$

where $t_{c}$ is start point of dead time, $i_{p}\left(t_{c}\right)$ is the constant value of the primary current during the dead time, $\mathrm{n}$ is the turn ratio, $V_{o}$ is the output voltage, $V_{D f}$ is the forward voltage drop of the secondary diode, and $T_{s}$ is the switching period.

At the high switching frequency, equation (1) cannot be retained during the dead time. Therefore, after $t_{c}$, the variation of the primary current during the dead time can be derived as follows:

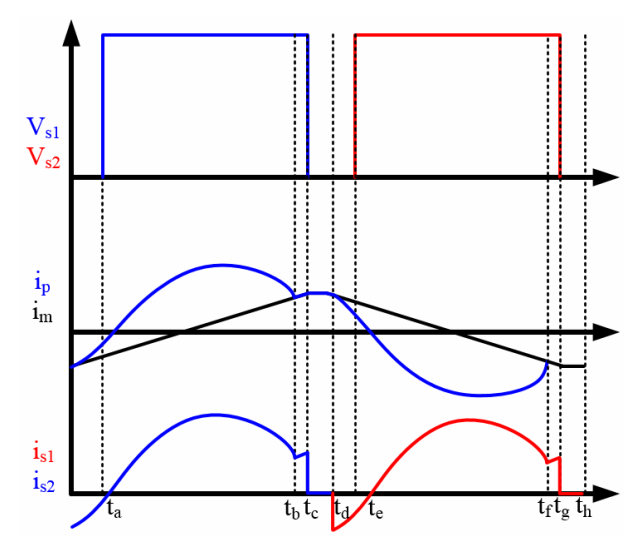

Fig. 3. Operational waveforms of the primary and the magnetizing current during the dead time 


$$
i_{p}(t)=i_{p}\left(t_{c}\right) \cos \omega_{r 1}(t)+\frac{V_{b}}{Z_{r 1}} \sin \omega_{r 1}(t)
$$

where $\omega_{r l}=2 \pi f_{r l}, V_{b}=V_{s}-V_{c r}-n\left(V_{o}+V_{D f}\right), V_{s}$ is input voltage, $f_{r l}$ is the resonant frequency between the leakage inductance and the resonant capacitor.

The conventional design guide of the magnetizing inductance shown in (3) has high error to obtain the ZVS condition with high dead time ratio.

$$
L_{m} \leq \frac{t_{d t}}{16 C_{s} f_{s, \max }}
$$

where $t_{d t}$ is the dead time duration, $C_{s}$ is the parasitic capacitance of primary side MOSFET, and $f_{s, \max }$ is the maximum switching frequency.

To obtain proper ZVS condition at the high switching frequency condition, equation (4) is proposed as follows:

$$
\frac{V_{s} t_{d t}}{8 L_{m}}\left(T_{s, \min }-2 t_{d t}\right) \geq 2 C_{s} V_{s}
$$

where $T_{s, \min }$ is switching period. Eq. (4) considers the current drop during the dead time. Assuming that magnetizing current is linear for the dead time, the current drop can be measured using the average primary current from the start of the dead time $\left(t_{c}, T_{s} / 4\right)$ to the end of the dead time $\left(t_{e}, T_{s} / 4-t\right)$. Using (4), a proper design guide of the magnetizing inductance to obtain the ZVS condition at the high switching frequency can be derived as follows:

$$
L_{m} \leq \frac{t_{d t}}{16 C_{s}}\left(T_{s, \min }-2 t_{d t}\right)
$$

Therefore, the magnetizing inductance which guarantee the ZVS of the MOSFET considering the high switching frequency operation with long dead time can be designed.

\subsection{Design for smaller output capacitance}

At the high switching frequency operation, small-size passive components such as transformer and output capacitor can be used in the converter for high power density. In the case of the output capacitance, the relationship between ESR (effective series resistance) and the output capacitance is important to analyze output voltage ripple as follows:

$$
\Delta V=E S R \times\left(\frac{\pi}{2}-1\right) \times I_{o}+\frac{\Delta Q}{C_{o}}
$$

where $I_{o}$ is the output current, $T_{s}$ is the switching period, and $\Delta Q=0.363 \times I_{o} T_{s}$.

The conventional converter uses high capacitance to reduce the output voltage ripple, but it is not effective

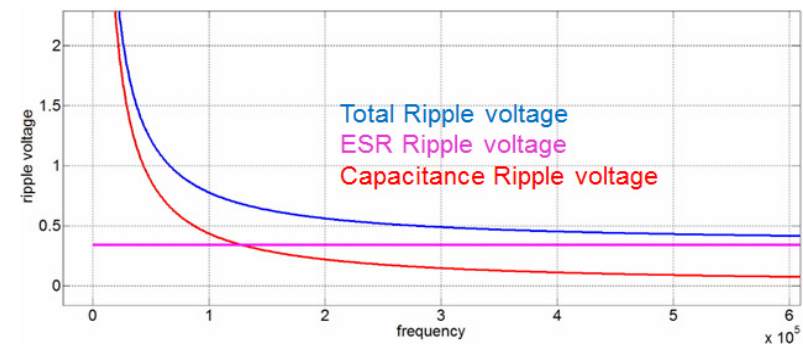

Fig. 4. Ripple voltage variation according to the switching frequency

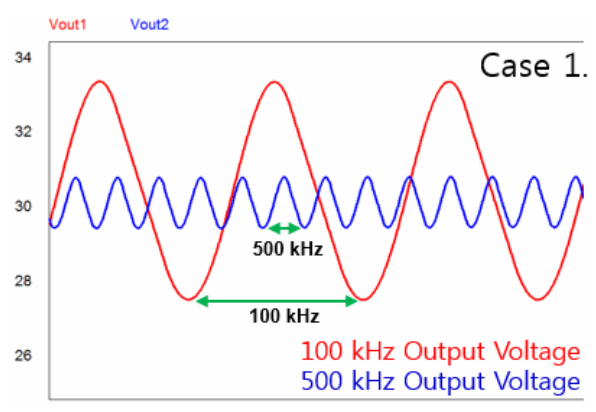

(a)

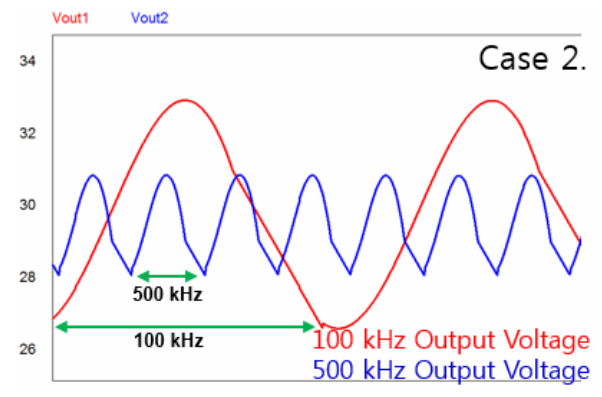

(b)

Fig. 5. Simulation waveform of output ripple voltage: (a) normal ESR, and small capacitance condition; (b) high ESR, and small capacitance condition

method to increase power density, because capacitance is proportional to the size of the capacitor. From (6), the voltage ripple related with the output capacitance is proportional to the output current and inversely proportional to the switching frequency. The voltage ripple from the ESR, however, is only related to the output current.

Fig. 4 shows output voltage ripple variations according to the switching frequency, which is derived from (6). Using Fig. 4 and (6), it is verified that the ESR is dominant factor to reduce the output voltage ripple than output capacitance at the high switching frequency. Therefore, the small ESR, and output capacitance is selected to improve the output voltage ripple, and the power density of the converter at the high frequency operation. The Table 1 and Fig. 5 show three simulation results to verify (6) and Fig. 4.

The case 1, which has normal ESR, and small capacitance condition, shows that capacitance is not dominant to the output voltage ripple at high frequency operation, comparing 
Table 1. Design specifications and simulation results of output ripple voltage

\begin{tabular}{|c|c|c|}
\hline \multicolumn{2}{|c|}{ Specification } & Value \\
\hline \multicolumn{2}{|c|}{ Input Voltage } & $420 \mathrm{~V}$ \\
\hline \multicolumn{2}{|c|}{ Output } & $30 \mathrm{~V} / 10 \mathrm{~A}$ \\
\hline Case 1 & Output Capacitance (ESR) & $3 \mu \mathrm{F}(15 \mathrm{~m} \Omega)$ \\
\hline Case 2 & Output Capacitance (ESR) & $3 \mu \mathrm{F}(100 \mathrm{~m} \Omega)$ \\
\hline \multicolumn{2}{|c|}{ Simulation Condition } & Output Ripple Voltage \\
\hline \multirow{2}{*}{ Case 1} & $100 \mathrm{kHz}$ & $5.84 \mathrm{~V}_{\mathrm{pk} p \mathrm{pk}}$ \\
\hline & $500 \mathrm{kHz}$ & $1.37 \mathrm{~V}_{\mathrm{pk} p \mathrm{pk}}$ \\
\hline \multirow{2}{*}{ Case 2} & $100 \mathrm{kHz}$ & $6.86 \mathrm{~V}_{\mathrm{pk} \mathrm{pk}}$ \\
\hline & $500 \mathrm{kHz}$ & $2.81 \mathrm{~V}_{\mathrm{pk} p \mathrm{pk}}$ \\
\hline
\end{tabular}

with normal frequency operation. The case 2, which has high ESR, and small capacitance condition, shows that ESR has a high effect on the output voltage ripple at high switching frequency.

\section{Design of High Frequency Magnetics}

The size of the transformer is determined by the crosssectional area of the core. Eqs. (7) and (8) show the relationship of the cross-sectional area using the faraday's law as follows:

$$
\begin{gathered}
V_{1}(t)=N_{p} \times \frac{d \Phi}{d t}=N_{p} \times \frac{d\left(B \times A_{c}\right)}{d t} \\
A_{c}=\frac{\bar{V}_{1} \times D \times T_{s}}{\Delta B \times N_{p}} \\
L=L_{m}+L_{l 1}+L_{l 2}=\frac{N_{p}^{2}}{\left(R_{c}+R_{g}\right)} \\
A_{c}=\frac{\left(D \times \bar{V}_{1}\right)^{2}}{\Delta B^{2} \times f_{s}^{2} \times L} \times \mu_{0} \times\left(\frac{\mu_{e}}{l_{e}}+\frac{1}{l_{g}}\right)
\end{gathered}
$$

where $A_{c}$ is the cross-sectional area, $V_{I}(t)$ is the input voltage, $\bar{V}_{1}$ is the average value of the input voltage, $D$ is the duty ratio, $\Delta B$ is the maximum flux density, $N_{p}$ is the primary turn number of the transformer, $\mu_{o}$ is the free-space permeability, $\mu_{e}$ is the relative magnetic permeability, $R_{c}$ is the reluctance of core, $R_{g}$ is the reluctance of air gap, $l_{e}$ is the effective magnetic length, and $l_{g}$ is the air gap length.

As shown in (8), the cross-sectional area is proportional to the input voltage, the duty ratio, and the switching period. It is inversely proportional to the maximum flux density and the primary turn number. In addition, $N_{p}$ in (8) can be substituted with (9) as shown in (10). In (10), the transformer permeability and the length of the air gap is derived from (8) and its air gap resistance. The size reduction of the transformer and the air gap length is proportional to the square of the switching frequency. Also, the small leakage and magnetizing inductance value at high switching frequency induces large air gap length.

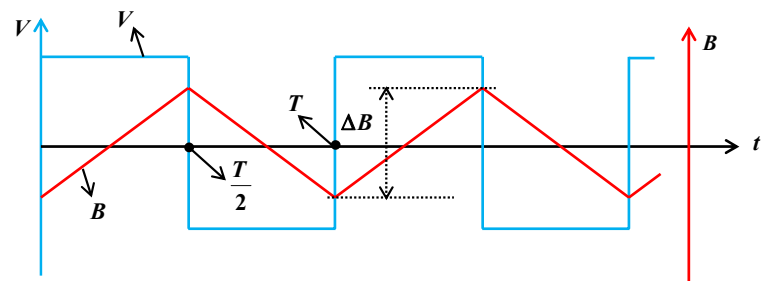

Fig. 6. Theoretical waveform of the input voltage and the flux density in the transformer

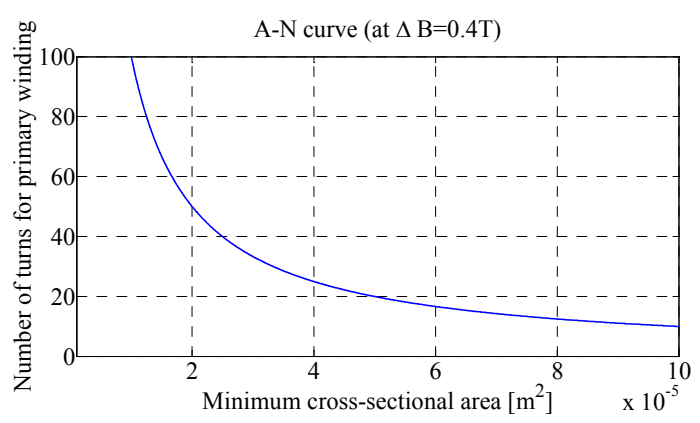

Fig. 7. Calculation results of the relation between $N_{p}$ and $A_{c, \min }$ at $500 \mathrm{kHz}$ switching frequency

Assuming that the square of $\Delta B$ and $\left(D \times V_{l}\right)$ is constant, the small-sized transformer can be used at $500 \mathrm{kHz}$ switching frequency since $\mu_{o}\left(\mu_{e} l_{e}^{-1}+l_{g}^{-1}\right)$ value increases about 2 times and the value of $\mathrm{L}$ decreases about 3.5 times. Consequently, the transformer size at $500 \mathrm{kHz}$ switching frequency can be reduced around 3.5 times than the transformer at $100 \mathrm{kHz}$ switching frequency.

\subsection{Design parameters for transformer}

Since the magnetic flux generated in a magnetic material should be limited before the magnetic core goes into saturation [22], the transformer should be designed to operate within the saturation limit of the flux density. When for the waveforms of the input voltage and the flux density in the transformer are as shown in Fig. 6, the relation of the design parameters from the Faraday's law can be obtained as follows $[21,22]$ :

$$
N_{p} \geq \frac{V}{\Delta B \cdot A_{\min } \cdot 2 f}
$$

where $N_{p}$ is the turn number of the primary winding in the transformer and $A_{\min }$ is the smallest cross-sectional area of the magnetic core. The duty-cycle is set by $50 \%$ since the core is designed for the LLC resonant converter.

Generally, the conventional ferrite core has a saturation flux density of around $0.4 \mathrm{~T}$. Therefore, available $\Delta B$ can be up to $0.8 \mathrm{~T}$. However, a sufficient margin in $\Delta B$ is required for half-bridge converters to prevent excessive hysteresis losses and heat generation [19]. Thus, $\Delta B$ should be much lower than $0.8 \mathrm{~T}$ and the value of $\Delta B$ is selected as 
Table 2. Design parameters of transformer

\begin{tabular}{c|c|c|c}
\hline Turn ratio & $N_{p}$ & $N_{s}$ & $A_{\min }\left[\mathrm{mm}^{2}\right]$ \\
\hline 10 & 30 & 3 & 33 \\
\hline
\end{tabular}

Table 3. Required values of resonant components

\begin{tabular}{c|c|c|c}
\hline Specification & $\begin{array}{c}\text { Magnetizing } \\
\text { inductance }\end{array}$ & $\begin{array}{c}\text { Leakage } \\
\text { inductance }\end{array}$ & $\begin{array}{c}\text { Resonant } \\
\text { capacitor }\end{array}$ \\
\hline $100 \mathrm{KHz}$ & $280 \mu \mathrm{H}$ & $80 \mu \mathrm{H}$ & $18 \mathrm{nF}$ \\
\hline $500 \mathrm{KHz}$ & $70 \mu \mathrm{H}$ & $10 \mu \mathrm{H}$ & $6 \mathrm{nF}$ \\
\hline
\end{tabular}

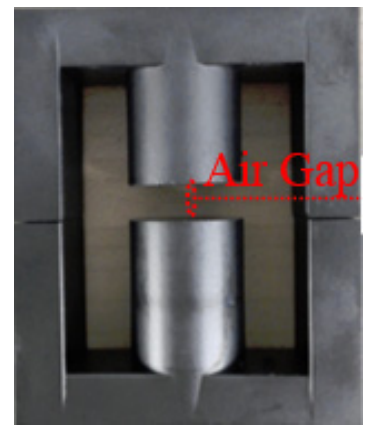

(a)

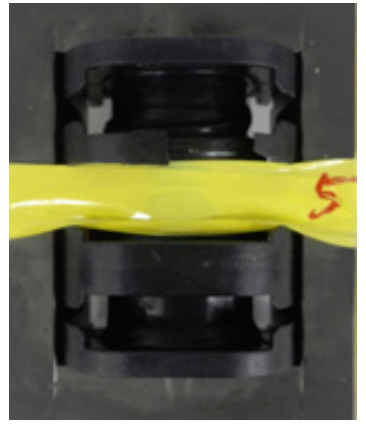

(b)
Fig. 8. Photo of the transformer for $500 \mathrm{kHz}$ LLC resonant converter: (a) EE core with an air gap to obtain the required magnetizing inductance; (b) Implemented transformer

$0.4 \mathrm{~T}$ in this paper. Fig. 7 is the calculated result of the variables of $N_{p}$ and $A_{\text {min }}$ for $500 \mathrm{kHz}$ switching frequency. From the calculated results, the proper size of the ferrite core can be chosen, which is not saturated at the switching frequency, with considering the window area of the windings. Table 2 shows the design parameters for the transformer at $500 \mathrm{kHz}$ operation.

\subsection{Magnetizing inductance and leakage inductance}

Table 3 presents design parameters of the magnetizing and leakage inductances for $100 \mathrm{kHz}$ and $500 \mathrm{kHz}$ switching frequency. To obtain the proper value of the magnetizing inductance, EE cores are used with an air gap as shown in Fig. 8 (a). By adjusting the air gap length, the magnetizing inductance can be obtained as follows:

$$
L_{m}=\frac{N_{p}^{2} \cdot \mu_{0} \cdot A_{g}}{l_{g}}
$$

where $l_{g}$ is the air gap length and $A_{g}$ is the cross-sectional area of the center leg.

Generally, the primary and secondary windings of the LLC resonant converter are separated to obtain large and controllable values of the leakage inductance for low switching frequency as shown in Fig. 9 (a) [23]. However, for the high frequency operation such as $500 \mathrm{kHz}$, the winding structure should be changed because a leakage

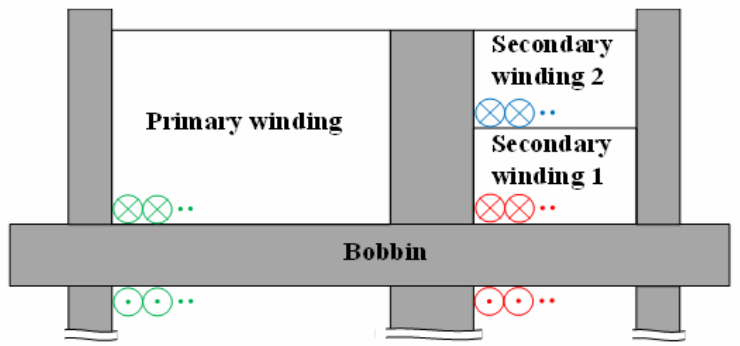

(a)

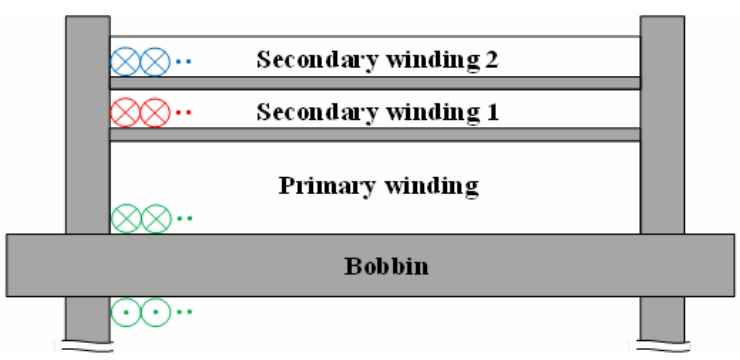

(b)

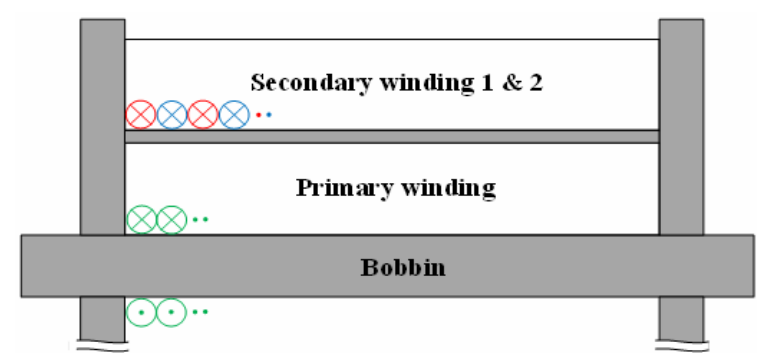

(c)

Fig. 9. Winding methods for the transformer used in the center-tapped LLC resonant converter: (a) conventional winding method; (b) overlapping winding method to obtain low leakage inductance; (c) bifilar winding method to obtain uniform leakage inductances

inductance in the LLC resonant converter is much smaller than the case of low frequency. In this case, the coupling between the primary and the secondary winding is too small as presented in Table 3. With the conventional winding structure presented in Fig. 9 (a), the leakage inductance will not be small enough.

To obtain the small leakage inductance, the overlapping winding method can be used as shown in Fig. 9 (b). However, applying the overlapping winding may result in an imbalance in the operation of the center-tapped LLC resonant converter, since the distance between the primary winding and the secondary winding 1 is different from the distance between the primary winding and the secondary winding 2 [7]. A small difference in the leakage inductances can be negligible at low frequency operation. However, at the high frequency operation, even small difference of the leakage inductances can cause abnormal operations. For example, $7 \mu \mathrm{H}$ difference of the leakage inductance has $10 \%$ error at $100 \mathrm{kHz}$ operation, while it has $70 \%$ error at $500 \mathrm{kHz}$. To obtain the balance of the leakage inductances in the secondary windings, the bifilar winding method is 


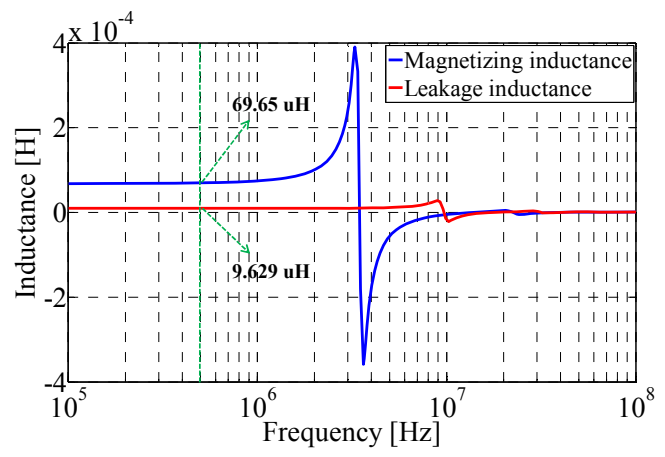

Fig. 10. Measured results of the magnetizing and leakage inductance designed for $500 \mathrm{kHz}$ operation

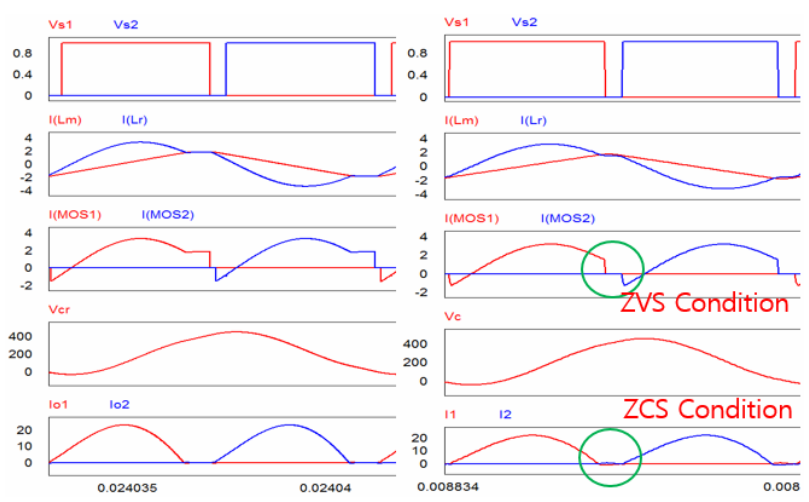

Fig. 11. Simulation results of $100 \mathrm{kHz}$ and $500 \mathrm{kHz}$ LLC resonant converter

applied as shown in Fig. 9 (c). By wrapping the secondary windings together alternately in the same layer, the leakage inductances of the secondary windings have the same value.

\subsection{Measurement Result}

Fig. 8 (b) shows an implemented transformer for the 500 $\mathrm{kHz}$ prototype converter with considering the calculated design parameters. The conductor of the secondary winding has parallel connections to ensure high output current.

Fig. 10 shows the measured results of the magnetizing and the leakage inductance of the implemented transformer shown in Fig. 8 (b).

The measurement is performed by an impedance analyzer, PSM1735 manufactured by N4L. In Fig. 10, the measured inductances satisfy the required design parameters in Table 3. The measured results show that the implemented transformer can be used in the proposed converter with proper magnetizing leakage inductance at $500 \mathrm{kHz}$ switching frequency.

\section{Results}

\subsection{Simulation results}

Fig. 11 shows the simulation results of the $100 \mathrm{kHz}$ and

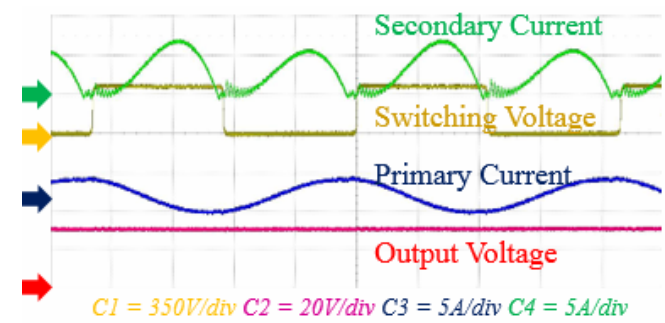

(a)

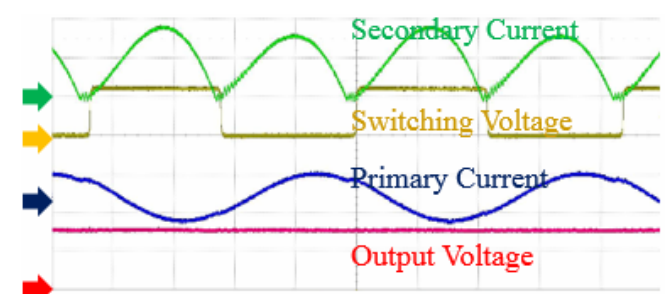

$C l=350 \mathrm{~V} / \mathrm{div} C 2=20 \mathrm{~V} / \mathrm{div} C 3=5 \mathrm{~A} / \mathrm{div} C 4=10 \mathrm{~A} / \mathrm{div}$

(b)

Fig. 12. Experimental waveforms of $100 \mathrm{kHz}$ LLC resonant converter: (a) $3 \mathrm{~A}$ light load case, (b) 10A full load case

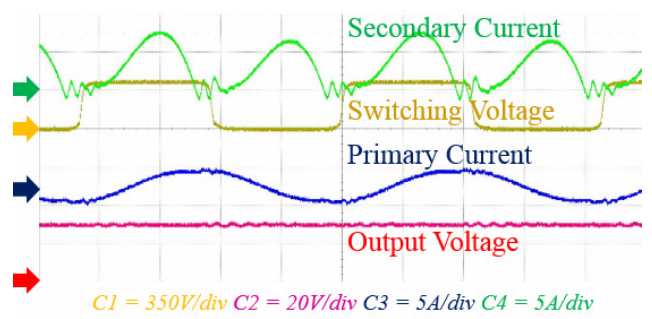

(a)

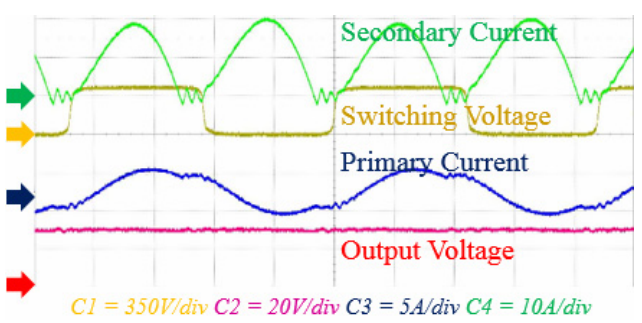

(b)

Fig. 13. Experimental waveforms of $500 \mathrm{kHz}$ LLC resonant converter: (a) $3 \mathrm{~A}$ light load case; (b) $10 \mathrm{~A}$ full load case.

$500 \mathrm{kHz}$ LLC resonant converter. At the $500 \mathrm{kHz}$ operation, the MOSFET operates under the ZVS condition, and the secondary diode is under a ZCS condition to reduce switching losses. Passive components used in this simulation are the same value shown in Table 3 .

\subsection{Experimental results}

Fig. 12 and 13 show that the $100 \mathrm{kHz}$ and $500 \mathrm{kHz}$ LLC resonant converters operate under the ZVS condition of the 


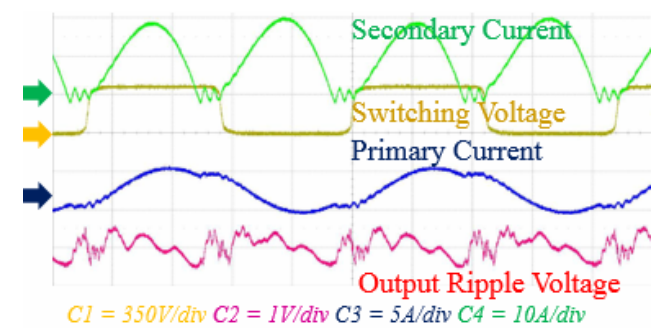

(a)

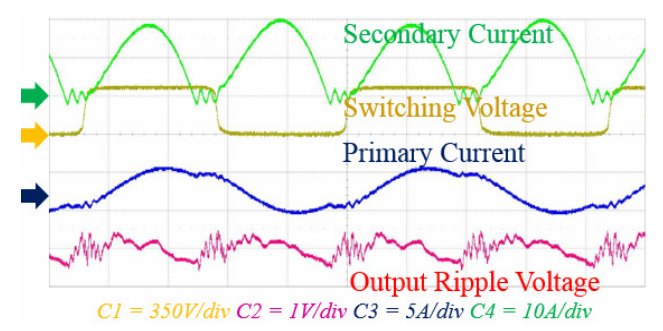

(b)

Fig. 14. Experimental waveforms of $500 \mathrm{kHz}$ output ripple voltage with $1047 \mu \mathrm{F}$ capacitor under full load condition: (a) output ripple voltage using $6600 \mu \mathrm{F}$; (b) output ripple voltage using $1047 \mu \mathrm{F}$

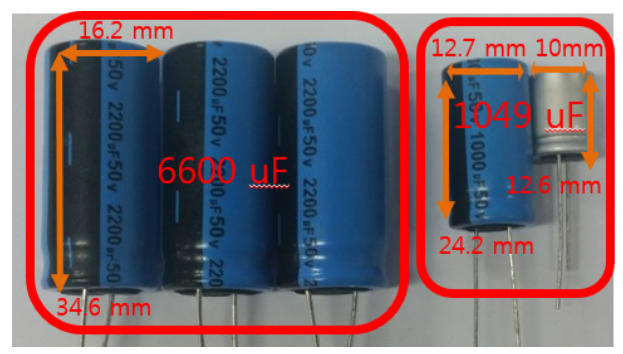

Fig. 15. Comparison of output capacitor sizes for $100 \mathrm{kHz}$ and $500 \mathrm{kHz}$ converters

MOSFET, and under the ZCS condition of the secondary diode. Comparing with the simulation results in Fig. 11, there is high frequency ringing in the waveform caused by parasitic capacitance and stray inductance in the practical prototype circuit. In Fig. 14, the output voltage ripple is measured to verify the validity of (6) and Fig. 4. In the case of high capacitance and high ESR condition $(6600 \mu \mathrm{F}$, $14 \mathrm{~m} \Omega$ ), the output voltage ripple is $1.21 \mathrm{~V}_{\mathrm{pk} \_\mathrm{pk}}$. In the case of small ESR and small capacitance condition $(1047 \mu \mathrm{F}$, $11.66 \mathrm{~m} \Omega)$, the output voltage ripple is $1.01 \mathrm{~V}_{\mathrm{pk} \mathrm{pk}}$. It means that small ESR is more dominant factor to reduce the output voltage ripple than high capacitance at the high switching frequency operation. The volume of the output capacitor is reduced around 5.2 times as shown in Fig. 15. The volume of the transformer is reduced around 1.3 times at the $500 \mathrm{kHz}$ switching frequency as shown in Fig. 16. From those results, the practical size of the output capacitor and the transformer.

Fig. 17 shows measured data of power conversion

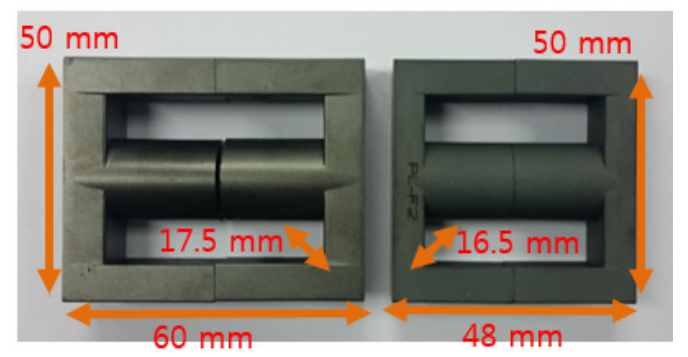

Fig. 16. Comparison of $100 \mathrm{kHz}$ and $500 \mathrm{kHz}$ transformer size

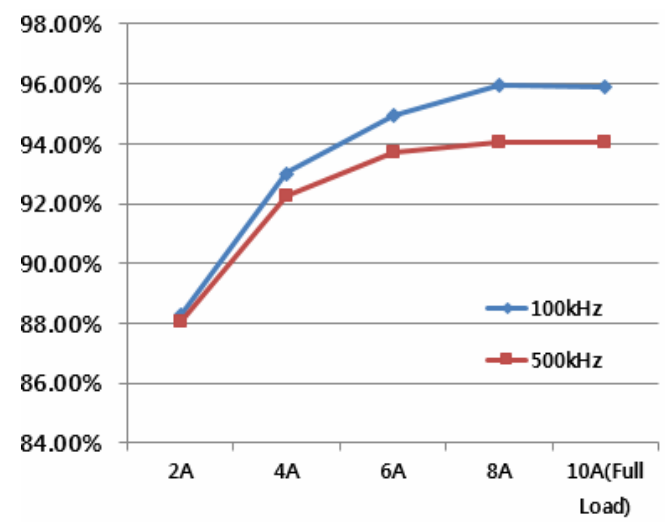

Fig. 17. Comparison of power conversion efficiency at 100 $\mathrm{kHz}$ and $500 \mathrm{kHz}$.

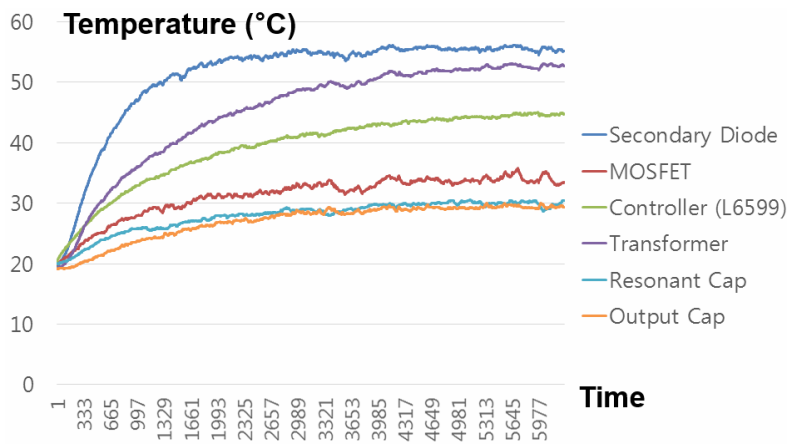

(a)

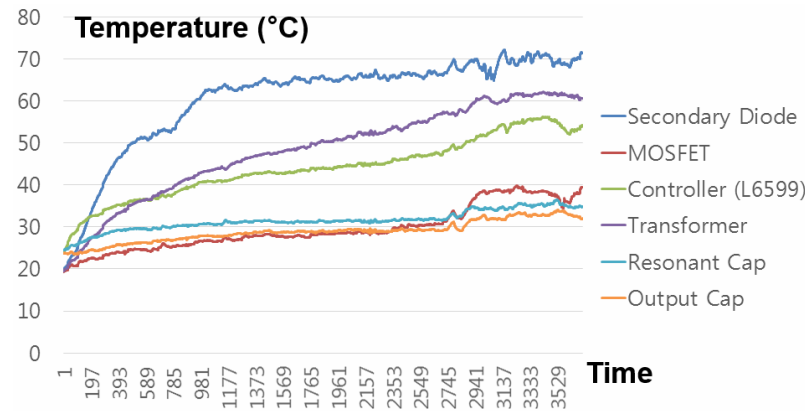

(b)

Fig. 18. Temperature variations of converters' components according to operating time: (a) $100 \mathrm{kHz}$ case; (b) $500 \mathrm{kHz}$ case. 
Table 4. Comparison of components temperature with respect to the switching frequency

\begin{tabular}{c|c|c}
\hline Specification & $100 \mathrm{kHz}$ & $500 \mathrm{kHz}$ \\
\hline Diode & $57^{\circ} \mathrm{C}$ & $71^{\circ} \mathrm{C}$ \\
\hline MOSFET & $35^{\circ} \mathrm{C}$ & $41^{\circ} \mathrm{C}$ \\
\hline L6599 (gate driver) & $45^{\circ} \mathrm{C}$ & $56^{\circ} \mathrm{C}$ \\
\hline Transformer & $51^{\circ} \mathrm{C}$ & $63^{\circ} \mathrm{C}$ \\
\hline Resonant capacitor & $33^{\circ} \mathrm{C}$ & $38^{\circ} \mathrm{C}$ \\
\hline Output capacitor & $31^{\circ} \mathrm{C}$ & $34^{\circ} \mathrm{C}$ \\
\hline
\end{tabular}

efficiency of the $100 \mathrm{kHz}$ and $500 \mathrm{kHz}$ prototype converters. Maximum efficiency of each switching frequency is $95.9 \%$ at the $100 \mathrm{kHz}$ and $94.0 \%$ at the $500 \mathrm{kHz}$, respectively.

At the $500 \mathrm{kHz}$, the power conversion efficiency is poorer than the case of $100 \mathrm{kHz}$ because of the more power losses caused by the faster switching and the more significant hysteresis effect. Power losses can be indirectly measured using temperature of each component as shown in Fig. 18.

The temperature is measured using ZR-RX25 (OMRON) with an ambient temperature of $20.6{ }^{\circ} \mathrm{C}$. Heat sinks $(25 \mathrm{~mm} \times 16.5 \mathrm{~mm} \times 16 \mathrm{~mm})$ are attached to all the switching components which have temperature variations as increasing the switching frequency. Table 4 shows the temperature variations with respect to the switching frequency. Comparing with the $100 \mathrm{kHz}$ operation, the switching components and the transformer have higher operating temperature. Other passive components also have the temperature increment, however, the difference is smaller than the case of the active and magnetic components.

\section{Conclusions}

In this paper, the design methodology is proposed for the high switching frequency LLC resonant converter to improve the power density in the practical manner. First, the design of proper magnetizing inductance is suggested to obtain the ZVS condition in the high frequency operation. Second, the design methods of small-sized passive components such as the output capacitor are derived. Third, the optimal transformer design for the high frequency operation is suggested to obtain the desirable inductance values. The proposed methodology and its validity for the high power density are verified using the simulation and the experimental results with $300 \mathrm{~W} 100 \mathrm{kHz}$ and $500 \mathrm{kHz}$ prototype converters. With the measured temperature and efficiency data, the dominant power losses could be analyzed in the high frequency operation.

\section{Acknowledgements}

This research was supported by the Basic Science
Research Program through the National Research Foundation of Korea (NRF) funded by the Ministry of Science, ICT \& Future Planning (NRF-2013R1A1A1009632).

\section{References}

[1] J. W. Kim and G. W. Moon, "A New LLC Series Resonant Converter with a Narrow Switching Frequency Variation and Reduced Conduction Losses," IEEE Trans. Power Electronics, Vol. 29, No. 8, pp. 4278-4287, Aug. 2014.

[2] Demirel. I and Erkmen. B, “A Very Low-Profile Dual Output LLC Resonant Converter for LCD/LED TV Application," IEEE Trans. Power Electronics, Vol. 29, No. 7, pp. 3514-3524, July. 2014.

[3] R. L. Steigerwald, "A Comparison of Half-Bridge Resonant Converter Topologies," IEEE Trans. Power Electronics, Vol. 3, No. 2, pp. 174-182, Apr. 1988.

[4] Yang. B, F. C. Lee, A. J. Zhang, H. Guisong, "LLC Resonant Converter for Front End DC/DC Conversion," in Proc. APEC '2002, Vol. 2, pp. 1108-1112, Mar. 2002.

[5] L. Bing, L. Wenduo, L. Yan, F. C. Lee, J. D. Van Wyk, "Optimal Design Methodology for LLC Resonant Converter," in Proc. APEC '2006, pp. 6, Mar. 2006.

[6] J. H. Jung and J. G. Kwon, "Theoretical Analysis and Optimal Design of LLC Resonant Converter," in Proc. EPE '2007, pp. 1- 10, Sept. 2007.

[7] J. H. Jung, "Bifilar Winding of a Center-Tapped Transformer Including Integrated Resonant Inductance for LLC Resonant Converter," IEEE Trans. Power Electronics, Vol. 28, No. 2, pp. 615-620, Feb. 2013.

[8] J. H. Jung, J. M. Choi, and J. G. Kwon, "Design Methodology for Transformers Including Integrated and Center-tapped Structure for LLC Resonant Converters," Journal of Power Electronics, vol. 9, no. 2, pp.215-223, Mar. 2009.

[9] H. P. Park, H. J. Choi, and J. H. Jung, "500 kHz High Frequency LLC Resonant Converter for High Power Density," in Proc. KIPE Annual Conference, pp. 189190, July 1-3 2014, Sokcho, Korea

[10] K. H. Yi, and G. W. Moon, "A Novel Two Phase Interleaved LLC Series Resonant Converter using a Phase of the Resonant Capacitor," Journal of Power Electronics, pp. 275-279, Jun. 2008.

[11] B. C. So, K. B. Seo, D. H. Lee, H. C. Jung, S. S. Hwang, H.W. Kim, K.Y. Cho, and B.K. Kim, "Design of LLC Resonant Converter having Enhanced Load Range for Communication Power," The Transactions of the Korean Institute of Power Electronics, Vol. 17, No. 5, pp. 461-469, Oct. 2012.

[12] H. S. Choi, "Design Consideration of Half-Bridge LLC Resonant Converter," Journal of Power Electronics, Vol. 7, No. 1, pp. 13-20, Jan. 2007.

[13] H. De Groot, E. Janssen, R. Pagano, K. Schetters, 
"Design of a 1-MHz LLC Resonant Converter Based on a DSP-Driven SOI Half-Bridge Power MOS Module," IEEE Trans. Power Electronics, Vol. 22, No. 6, pp.2307-2320, Nov. 2007.

[14] H. S. Kim, J. W. Baek, M. H. Ryu, J. H. Kim, and J. H. Jung, "High Efficiency Isolated AC-DC Converter Using Three-Phase Interleaved LLC Resonant Converter Employing Y-Connected Rectifier," IEEE Trans. Power Electronics, vol. 29, no. 8, pp. 40174028, Aug. 2014.

[15] F. Dianbo, F. C. Lee, L. Ya, X. Ming, "Novel MultiElement Resonant Converter for Front-end DC/DC Converters," in Proc. PESC '2008, pp. 250-256, Jun. 2008.

[16] S. S. Hong, S. H. Cho, C. W. Roh, and S. K. Han, "Precise Analysis Solution for the Peak Gain of LLC Resonant Converters," Journal of Power Electronics, pp. 680-685, Nov. 2010.

[17] F. Dianbo, L. Bing, F. C. Lee, "1MHz High Efficiency LLC Resonant Converter with Synchronous Rectifier,' in Proc. PESC '2007, pp. 2404-2410, Jun. 2007

[18] Z. Weimin, X. Zhuxian, Z. Zhang, F. Wang, L. M. Tolbert, B. J. Blalock, "Evaluation of $600 \mathrm{~V}$ Cascade GaN HEMT in Device Characterization and all-GaNbased LLC Resonant Converter," in Proc. ECCE '2013, pp. 3571-3578, Sept. 2013.

[19] M. D. Seeman, S. R. Bahl, D. I. Anderson, G. A. Shah, "Advantages of $\mathrm{GaN}$ in a High-voltage Resonant LLC Converter," in Proc. APEC '2014, pp. 476-483, Mar. 2014.

[20] D. Huang, S. Ji, F. C. Lee, "LLC Resonant Converter with Matrix Transformer," IEEE Trans. Power Electronics, Vol. 29, No. 8, pp. 4339-4347, Aug. 2014.

[21] H. Schmidt-Walter, http://schmidt-walter.eit.h-da.de/, Mar. 19th 2001.

[22] C. W. T. Mclyman, Transformer and Inductor Design Handbook, 4th ed., CRC Press, 2011.

[23] Y. Ryu, S. Kim, G. Jeong, J. Park, D. Kim, J. Park, J. Kim and K. J. Han, "Common Mode Noise Reduction for an LLC Resonant Converter by Using Passive Noise Cancellation," Journal of Electromagnetic Engineering and Science, vol. 15, no. 2, pp. 8996, Apr. 2015.

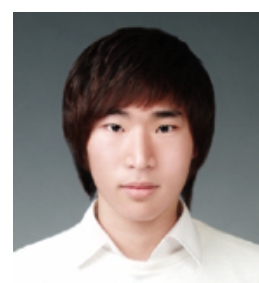

Hwa-Pyeong Park He received B.S degree in electrical engineering from Koreatech in 2013. His research interests are high switching frequency converter, switch mode power supply, and digital control algorithm.

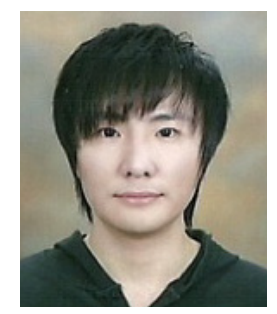

Younggon Ryu He received B.S degree in electrical engineering from University of Ulsan, Ulsan, Korea, in 2008. He is currently working toward the Ph.D. degree with the School of Electrical and Computer Engineering, Ulsan National Institute of Science and Technology, Ulsan, Korea. His research interests include high frequency modeling and design for electrical machines.

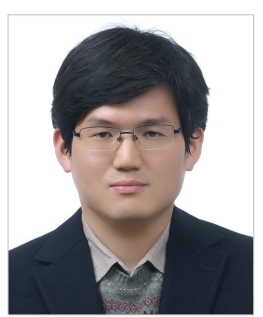

Ki Jin Han $\mathrm{He}$ received the B.S. (summa cum laude) and M.S. degrees in electrical engineering from Seoul National University, Seoul, Korea, in 1998 and 2000, respectively, and the $\mathrm{Ph} . \mathrm{D}$. degree in electrical and computer engineering from the Georgia Institute of Technology, Atlanta, GA, USA, in 2009. He was with the System Research and Development Laboratory, LG Precision Co., Ltd., Yongin, Korea, from 2000 to 2005. From 2009 to 2011, he was with the IBM Thomas J. Watson Re search Center, Yorktown Heights, NY, USA, from 2009 to 2011, as a Post-Doctoral Researcher. He is currently with the School of Electrical and Computer Engineering, Ulsan National Institute of Science and Technology, Ulsan, Korea, as an Associate Professor. His current research interests include EMC for power electronics, computational electromagnetics, and electronic packaging. Dr. Han was a recipient of the Samsung Scholarship for graduate study in 2005.

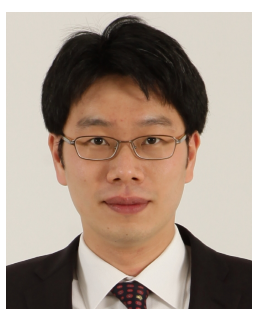

Jee-Hoon Jung He was born in Suwan, Korea, in 1977. He received the B.S., M.S., and Ph.D. degree from Pohang University of Science and Technology (POSTECH), Pohang, Korea, in 2000, 2002, and 2006, respectively. From 2006 to 2009, he was a Senior Research Engineer with the Digital Printing Division, Samsung Electronics Company Ltd., Suwon, Korea. From 2009 to 2010, he was a Postdoctoral Research Associate with the Department of Electrical and Computer Engineering, Texas A\&M University of Qatar, Doha, Qatar. From 2011 to 2012, he was a Senior Researcher with the Power Conversion and Control Research Center, HVDC Research Division, Korea Electro technology Research Institute, Changwon, Korea. Since 2013, he has been an Assistant Professor with the School of Electrical and Computer Engineering, Ulsan National Institute of Science and Technology, Ulsan, Korea. His research interests include $\mathrm{dc}-\mathrm{dc}$ converters, switched-mode power supplies, motor drives and diagnosis systems, digital control and signal processing algorithms, digitally controlled power electronics, 
power conversion for renewable energy, and real-time and power hardware-in-the-loop simulations (HILS) of renewable energy sources. Recently, he has been researching high frequency power converters using wide bandgap devices, smart power transformers for smart grids, power control algorithms for dc microgrids, and wireless power transfer techniques for electric vehicle and home appliance applications.

Dr. Jung is a Senior Member of the IEEE Industrial Electronics Society, the IEEE Power Electronics Society, the IEEE Industry Applications Society, and the IEEE Power and Energy Society, and he is an Associated Editor of Journal of Power Electronics and a member of the Editorial Committee of the Korea Institute of Power Electronics. 